\title{
O PAPEL HISTÓRICO DA INSERÇÃO DA MULHER NO MERCADO DE TRABALHO E SUA DUPLA JORNADA
}

\section{ARTIGO ORIGINAL}

ARAÚJO, Gizelda Rodrigues de ${ }^{1}$, FREITAS, Josiane Machado Fagundes ${ }^{2}$, SOUZA, Nayara Aryan Melo $^{3}$

ARAÚJO, Gizelda Rodrigues de. FREITAS, Josiane Machado Fagundes. SOUZA, Nayara Aryan Melo. $O$ papel histórico da inserção da mulher no mercado de trabalho e sua dupla jornada. Revista Científica Multidisciplinar Núcleo do Conhecimento. Ano 06, Ed. 11, Vol. 04, pp. 76-97. Novembro de 2021. ISSN: 24480959, Link de acesso: https://www.nucleodoconhecimento.com.br/historia/insercaoda-mulher

\section{RESUMO}

Esse estudo objetiva compreender o papel histórico da participação feminina no mercado de trabalho, bem como a articulação entre o trabalho doméstico e remunerado. Partiu-se do seguinte questionamento: como se estabelece as relações

\footnotetext{
${ }_{1}^{1}$ Pós-graduanda de Direito Civil - PUC-Minas; Pós-graduada em Biologia pela UFLA; Pós- graduada em Gestão ambiental pela FASEM; pós-graduada em Métodos e técnicas de ensino pela UNIVERSO; Graduanda em Direito pela UEG; Graduada em Física pela UFG; Graduada em Biologia pela UEG; Graduada em Pedagogia pela UEG.

2 Pós-graduada em Docência do Ensino Superior- UEG/ Uruaçu- GO; Pós-graduada em Gestão Pública/ UEG/ Uruaçu-GO. Graduada em Licenciatura em História- GO; Graduando em Bacharelado em Direito- UEG/ Uruaçu-GO.

${ }^{3}$ Graduação em Fisioterapia - Universidade Estadual de Goiás. Pós-Graduada em Gestão em Saúde - Universidade Estadual de Goiás. Graduanda em Direito Universidade Estadual de Goiás. Pós-Graduanda em Direito do Trabalho e Processo do Trabalho - Instituto Verbo Jurídico.
} 
entre as desigualdades de gênero e as dificuldades das mulheres na articulação entre o trabalho doméstico e o trabalho remunerado? Dessa forma, é justificável essa pesquisa pela observância da realidade no concerne à dupla jornada, ou até mesmo tripla jornada, das mulheres uruaçuenses, a qual se verifica a concomitância do trabalho remunerado com os afazeres domésticos, e em muitos casos, ainda, o estudo. $\mathrm{O}$ artigo em questão se trata de uma pesquisa de campo e, de uma pesquisa bibliográfica de cunho exploratório, desenvolvido com uma amostragem de 50 mulheres, na zona urbana de Uruaçu, escolhidas de forma aleatória, mediante um questionário de 16 perguntas, objetivas e subjetivas, com o propósito de investigar se as mulheres uruaçuenses também compartilham desta dupla jornada. Conclui-se, então, que se faz necessário maiores investimentos em políticas públicas no sentido de garantir uma valorização trabalhista, até mesmo em termos de direitos previdenciários, uma vez que esse quantitativo de horas trabalhadas pelas mulheres, não são contabilizadas para efeitos de aposentadoria.

Palavras-Chave: Mulher, gênero, dupla jornada, direitos.

\section{INTRODUÇÃO}

O legado histórico da colonização e desenvolvimento econômico baseado na escravidão e na exploração da população negra, somados a uma cultura patriarcal vivenciada desde os primórdios, em que o chefe da casa era sempre superior a mulher, viabiliza um fenômeno invisível às políticas públicas: a dupla jornada de trabalho da mulher.

Mesmo diante de tantas mudanças ocorridas no século XXI, como transformações econômicas, políticas, tecnológicas e sociais e mediante algumas alterações significativas na condição feminina como, o aumento de escolaridade, a diminuição do tamanho das famílias, a entrada e permanência no mercado de trabalho e o aumento dos domicílios chefiados por mulheres, ainda assim, um dos pontos de maior tensão na vida dessas mulheres é a articulação entre o trabalho remunerado (produtivo) e o trabalho doméstico (reprodutivo). 
A ascensão das mulheres no mercado de trabalho trouxe à tona a questão denominada de dupla jornada de trabalho, na qual atuam como profissionais e ao mesmo tempo como mães, esposas e donas de casa.

Dados da "Síntese de Indicadores Sociais (SIS) - Uma análise das condições de vida da população brasileira 2014" publicada pelo Instituto Brasileiro de Geografia e Estatística (IBGE), mostra que a dupla jornada feminina afeta mais mulheres do que os homens. Segundo a pesquisa, $88 \%$ das mulheres brasileiras ocupadas, de 16 anos ou mais de idade realizam afazeres domésticos. Dentre os homens, apenas $46 \%$. A conclusão do estudo mostra que, ao juntar a atuação das mulheres no mercado de trabalho com as atividades do lar, tem-se uma jornada feminina semanal total de 56,4 horas, que supera em quase cinco horas a jornada masculina (IBGE, 2019).

A partir de então, este artigo pretende compreender a dupla jordana feminina que coincide o trabalho com as atividades domésticas. Bem como, entender como a sociedade brasileira, formada a partir do patriarcalismo e da escravidão orientou a inserção das mulheres na sociedade, assim como a articulação entre o trabalho doméstico e o remunerado. Nesse sentido, sabendo da dupla jornada laboral que a mulher enfrenta, questiona-se: como se estabelece as relações entre as desigualdades de gênero e as dificuldades das mulheres na articulação entre o trabalho doméstico e o trabalho remunerado?

O referido trabalho vem realçar a busca incessante das mulheres pelo mercado de trabalho, o que não se dá apenas pela necessidade financeira, mas também pela realização pessoal e profissional, isto é, "a mulher procura firmar sua identidade pessoal para além dos limites do lar, buscando satisfação na execução de projetos pessoais, que envolvem um trabalho profissional e uma carreira" (LADEIRA, 2000, p. 2).

Dessa forma, é justificável essa pesquisa pela observância da realidade no que concerne a dupla jornada, ou até mesmo tripla jornada, das mulheres uruaçuenses, a qual se verifica a concomitância do trabalho remunerado com os afazeres domésticos, e em muitos casos, ainda, o estudo. 
Conforme Matos e Borelli (2012), mesmo com a ampliação da presença das mulheres no mercado produtivo, grande parte delas tem que lidar com a dupla jornada de trabalho - remunerado e doméstico -, incluindo cuidados com a família, o que sobrecarrega o seu cotidiano com inúmeras solicitações. Observa-se que desde que a mulher adentrou no mercado de trabalho, ela tem desempenhado de forma geral, uma dupla ou tripla jornada de trabalho.

\section{PROCEDIMENTOS METODOLÓGICOS}

O estudo em questão se trata de uma pesquisa de campo, a qual Lakatos e Marconi (2003) definem como sendo aquela utilizada com o objetivo de conseguir informações e/ou conhecimentos acerca de um problema, para o qual se procura uma resposta, ou de uma hipótese, que se queira comprovar, ou ainda, descobrir novos fenômenos ou as relações entre eles.

Também, trata-se de uma pesquisa bibliográfica, visto que foi a partir do levantamento de referências teóricas, publicadas por meios escritos e eletrônicos, como livros, artigos científicos, entre outros, que se recolheram informações ou conhecimentos prévios sobre o problema do qual se procura uma resposta.

Segundo Lakatos e Marconi (2003, p. 43), este tipo de pesquisa não é "mera repetição do que já foi dito ou escrito sobre certo assunto, mas propicia um exame de um tema sob novo enfoque ou abordagem, chegando a conclusões inovadoras".

Quanto ao objetivo, trata-se de uma pesquisa exploratória em virtude de o levantamento de dados ter sido feito através de pesquisa bibliográfica e pesquisa de campo. De acordo com Gil (2008), este tipo de pesquisa tem como objetivo proporcionar maior familiaridade com o problema, com vistas a torná-lo mais explícito ou a construir hipóteses.

Salienta-se, assim, que o desenvolvimento dessa pesquisa ocorreu via questionário contendo 16 (dezesseis) questões, com perguntas abertas e fechadas, elaborado pelas pesquisadoras no intuito de perceber se a dupla jornada de trabalho se fazia presente na vida das mulheres uruaçuenses. A pesquisa contou com uma 
amostragem de 50 (cinquenta) mulheres de diferentes etnias, grau de instrução, estado civil, dentre as diversas classes sociais e procurou-se aplicar o referido questionário em diferentes pontos da cidade, tais como: universidade (curso de Pedagogia), escolas, locais de públicos e outros. A coleta dos dados ocorreu entre os dias 27 e 30 de maio de 2019 na cidade de Uruaçu-Go.

\section{INSERÇÃO DA MULHER NO MERCADO DE TRABALHO E SUA DUPLA JORNADA}

Pode se dizer que, culturalmente, sempre foi atribuída às mulheres a responsabilidade das inúmeras tarefas conhecidas coletivamente como "tarefas domésticas": cozinhar, lavar louça, lavar roupa, passar roupa, fazer a cama, varrer, comprar, dentre tantas outras e ainda cuidar das crianças, dos idosos e de pessoas com deficiências, ou seja, atividades não remuneradas no âmbito privado.

Estatisticamente comprovado pelo Instituto de Pesquisa Econômica Aplicada (IPEA) que as atividades domésticas consomem de três mil a quatro mil horas anuais e isso sem contabilizar a variável e inquantificável atenção que as mães dão aos filhos (PINHEIRO, 2018).

Observa-se com isso que o labor doméstico é interminável e ao mesmo tempo invisível, visto que ninguém a nota, a não ser que não esteja feito. Além disso, é considerado improdutivo, rotineiro, repetitivo e cansativo fazendo com que as mulheres se sintam muitas vezes escravas[4] dentro de sua própria casa e não remunerado (SILVA et al., 2017).

Conclui-se então, em termos sociais e culturais no aspecto ocidental, que se atribui às mulheres a responsabilidade das atividades não remuneradas no âmbito privado, enquanto para os homens caberia a parcela maior de produção mercantil remunerada no espaço público. Percebe-se com isso, que apesar da crescente incorporação da mulher no mercado de trabalho, elas não conseguem se desvincular do papel social a elas designado, gerando sobrecarga física e as impedindo de participar equitativamente das oportunidades. 
Complementando esse pensamento, Bourdieu (1999), enfatiza que, mesmo com o acesso ao ensino secundário e superior e ao trabalho assalariado, além da evolução do uso de métodos contraceptivos que representam transformações importantes pelas quais as mulheres passaram, ainda assim elas não se desvencilharam dos afazeres que realizam em casa antes e depois do trabalho fora de casa, visto que há uma naturalização desses papéis, como inerentes da mulher.

Nestes termos, vale ressaltar o pensamento de Simone Beauvoir (1967, p. 135) sobre a condição da mulher: "[...] ninguém nasce mulher, torna-se mulher. Nenhum destino biológico, psíquico, econômico define a forma que a fêmea humana assume no seio da sociedade $[\ldots] "$.

Nesse sentido indaga-se: Por que as meninas foram educadas para lidar com as tarefas domésticas? Adota-se a ênfase de um modelo nuclear de família, no qual o homem seria o chefe de família, o provedor, encarregado de sustentar a família, enquanto a mulher, a dona da casa, cuidaria do lar, dos filhos, do marido e de quem se alojasse em sua casa.

$\mathrm{Na}$ ordem patriarcal, a mulher deveria obedecer a pai e marido, passando da autoridade de um para a do outro através de um casamento monogâmico e indissolúvel. O domínio masculino era indiscutível. Os projetos individuais e as manifestações de desejos e sentimentos particulares tinham pouco ou nenhum espaço quando o que importava era o grupo familiar e, dentro dele, a vontade do seu chefe, ou patriarca, era soberana (SCOTT, 2012, p. 16).

Entretanto, cabe sobrelevar que esse modelo padrão, em que o homem era o único provedor, há muito se esfacelou, pelo grande número de mulheres inseridas no mercado de trabalho ajudando nas despesas da casa e na maioria das vezes, sustentando a casa sozinha. E neste contexto, Martins (2003, p. 5) expõe sobre as relações assimétricas de poder entre os gêneros:

As desigualdades de gênero no Brasil expressam-se através de aspectos diversos, abrangendo a esfera tanto pública como privada. Nesse contexto, constata-se que, mesmo após mais de um século de grandes mudanças políticas e sociais, período no qual a clivagem entre os tradicionais papéis masculino e feminino tem sido questionada, as relações assimétricas de poder entre os gêneros ainda se mantêm, determinando uma ascensão desigual das mulheres 
em relação às oportunidades econômicas e sociais que compõem o processo de desenvolvimento.

Nesse sentido, considerando o equilíbrio entre o trabalho remunerado e as atividades domésticas que continuam sob a responsabilidade da mulher, o indicador de uso do tempo, elaborado com os dados da PNAD-IBGE (Pesquisa Nacional por Amostra de Domicílios - Instituto Brasileiro de Geografia e Estatística) e dado de referência da CEPAL (Comissão Econômica para a América Latina e o Caribe) e da OIT-ONU (2011), demonstram a desigualdade de gênero, apresentando o peso da dupla jornada para as mulheres brasileiras com 16 anos ou mais, evidenciando o total de horas semanais dedicadas ao mercado de trabalho somadas as horas que dedica aos afazeres domésticos e compara com a carga horária semanal do homem, onde se observa uma grande disparidade de acordo com a tabela 01 .

Tabela 01: Número médio de horas semanais dedicadas ao mercado de trabalho e aos afazeres domésticos pela população ocupada de 16 anos ou mais de idade no Brasil e em unidades da federação selecionados em 2011.

\begin{tabular}{|c|c|c|c|c|c|c|c|}
\hline \multirow[t]{2}{*}{$\begin{array}{l}\text { ÁREA } \\
\text { GEOGRÁFI } \\
\text { CA }\end{array}$} & \multicolumn{2}{|c|}{$\begin{array}{l}\text { MERCADO DE } \\
\text { TRABALHO } \\
\text { (A) }\end{array}$} & \multicolumn{2}{|c|}{$\begin{array}{l}\text { AFAZERES } \\
\text { DOMÉSTICOS } \\
\text { (B) }\end{array}$} & \multicolumn{2}{|c|}{$\begin{array}{l}\text { JORNADA } \\
\text { SEMANAL } \\
\text { TOTAL }(A+B)\end{array}$} & \multirow[t]{2}{*}{$\begin{array}{l}\text { CLASSIFICA } \\
\text { ÇÃO }\end{array}$} \\
\hline & $\begin{array}{l}\text { Home } \\
\text { ns }\end{array}$ & $\begin{array}{l}\text { Mulher } \\
\text { es }\end{array}$ & $\begin{array}{l}\text { Home } \\
\text { ns }\end{array}$ & $\begin{array}{l}\text { Mulher } \\
\text { es }\end{array}$ & $\begin{array}{l}\text { Home } \\
\text { ns }\end{array}$ & $\begin{array}{l}\text { Mulher } \\
\text { es }\end{array}$ & \\
\hline Brasil & 42,6 & 36,9 & 10,3 & 21,8 & 52,9 & 58,7 & - \\
\hline Alagoas & 41,0 & 34,6 & 13,2 & 28,6 & 54,2 & 63,1 & $1^{0}$ \\
\hline Amapá & 44,0 & 38,8 & 12,0 & 23,3 & 56,0 & 62,1 & $2^{0}$ \\
\hline $\begin{array}{l}\text { Pernambu } \\
\text { co }\end{array}$ & 41,4 & 37,4 & 13,3 & 24,5 & 54,8 & 61,9 & $3^{\circ}$ \\
\hline Ceará & 42,0 & 36,8 & 12,0 & 24,7 & 54,0 & 61,5 & $4^{\circ}$ \\
\hline São Paulo & 43,7 & 38,9 & 9,9 & 29,8 & 53,5 & 59,8 & $5^{\circ}$ \\
\hline $\begin{array}{l}\text { Rio Grande } \\
\text { do Sul }\end{array}$ & 44,0 & 38,1 & 10,3 & 21,1 & 54,3 & 59,1 & $10^{\circ}$ \\
\hline
\end{tabular}

Fonte: IBGE/dados do PNAD - 2011. 
Observa-se que embora a tabela apresente que as mulheres em 2011 no Brasil tinham uma carga horária semanal no mercado de trabalho menor do que dos homens (36,9\% e $42,6 \%$, respectivamente), elas dedicavam $21,8 \%$ horas semanais com afazeres domésticos (não remunerado) enquanto o homem, apenas 10,3\%. (PNAD/IBGE, 2011)

Nota-se ainda que no final da semana a jornada dupla da mulher chegava a 58,7\% contra $52,9 \%$ dos homens. E vale ressaltar ainda, de acordo com pesquisa realizada pelo Instituto de Pesquisa Econômica Aplicada - IPEA (2010), que os afazeres domésticos do homem se restringiam apenas em compras ao supermercado e levar crianças na escola, alguns reparos e consertos domésticos esporádicos, ficando as demais tarefas para as mulheres.

De acordo com a pesquisa do PNAD/IBGE (2011), a jornada de trabalho das mulheres se mostrou mais extensa que dos homens, principalmente, nos estados de Alagoas, Amapá, Ceará, Pernambuco, São Paulo e Rio Grande do Sul, conforme mostra tabela 01, acima. E dentre estes, chama a atenção o estado de Alagoas que ocupa a $1^{\underline{a}}$ posição no ranking com $63,1 \%$ horas totais de trabalho semanais das mulheres, sendo que 28,6 horas são dedicadas aos afazeres domésticos.

Dentro deste mesmo contexto, em 2015 o IPEA (2015) observou que a proporção de famílias chefiadas por mulheres chegou a $40 \%$. Além do fato, das mulheres estarem trabalhando mais devido à dupla jornada e ganhando menos que os homens, apesar do grau de escolaridade ser mais alto entre elas.

Entende-se, mediante o exposto, que o patriarcalismo da sociedade brasileira ainda se faz presente, na medida em que grande parte das mulheres além de exercer sua vida profissional com uma carga exaustiva, ainda executam as diferentes tarefas domésticas, em virtude de carregarem a obrigação de serem responsáveis pela casa, pelos filhos e ainda cuidar do marido. Obrigação, esta, não observada pelos homens com a mesma intensidade. 
De maneira geral, o pensamento social brasileiro, no que diz respeito a posição da mulher, ainda está enraizado na casa grande e senzala. E é neste contexto que os conflitos surgem numa tentativa de articulação entre o trabalho não remunerado e o trabalho remunerado, pois as mulheres avançaram no mercado de trabalho e em contrapartida os homens ainda estão muito aquém na esfera doméstica (BARBOSA, 2017).

Compartilhando esse pensamento, Del Priori (2004, p. 472) vem ressaltar como os homens desacreditavam e desvalorizavam o trabalho da mulher, todavia, fica explícito a força e a determinação dela.

Com a passagem do regime de colonato para o assalariamento, as mulheres ganharam ainda a dupla jornada de trabalho. No espaço da casa, as mulheres continuaram arcando com todo o trabalho doméstico, realizado durante uma jornada extensa e intensíssima. Suas vidas, especialmente se mães, resumem-se ao trabalho. Levantam-se, em geral, às $4 \mathrm{~h}$ da manhã, preparam a comida para elas e os demais membros da família que trabalham fora e também para os que ficam na casa. Às 6 h, "pegam" o caminhão ou ônibus para uma jornada de trabalho de nove a dez horas, inclusive aos sábados. Ao chegarem a casa, por volta das $18 \mathrm{~h}$ ou $19 \mathrm{~h}$, ainda vão preparar o jantar, lavar roupa, limpar a casa e cuidar dos filhos, podendo receber ajuda de outras mulheres, pois a participação masculina no trabalho doméstico é muito rara. Nunca dormem mais de seis horas por dia. Aos domingos, dedicam-se às tarefas domésticas. Raramente, sobraIhes tempo para o lazer (DEL PRIORI, 2004, p. 472)

O quadro apresentado por Del Priori (2004) não se distancia do atual em que as mulheres contemporâneas se debatem entre conciliar antigos e novos papéis, na tentativa de equilibrar as atribuições no trabalho, na vida pessoal e na família.

Há que se observarem no âmbito das políticas públicas, estratégias para a promoção de igualdade de gênero no mundo do trabalho, principalmente no tocante a quantidade de horas trabalhadas pela mulher no espaço privado para que se possa repensar as formas de organização do trabalho nas suas diferentes esferas, bem como os direitos previdenciários dela.

Por muito tempo as tarefas domésticas foram consideradas como um "não trabalho" em virtude de implicar numa reprodução da vida social, vindo assim acarretar uma 
sobrecarga para a mulher atualmente, que tentam se desdobrar para conseguir conciliares os afazeres domésticos com o trabalho no âmbito público.

Complementando esse pensamento Martins (2011) assevera que a mulher continua com uma carga maior nos afazeres domésticos.

No que se refere ao mundo do trabalho, as diferenças históricas entre homens e mulheres em relação a acesso ao mercado de trabalho formal, condições de remuneração, empregabilidade, proteção social e direitos trabalhistas fundamentais somam-se a uma carga maior para o sexo feminino no diz respeito aos respeitos aos afazeres domésticos. (MARTINS, 2011)

Ainda com respeito à jornada de trabalho da mulher e os direitos adquiridos, Thueler e Bandeira (2010), vem dizer que, a Constituição de 1988 foi um marco no percurso dessa conquista de direitos, os quais se encontram expressos no art. 5o, I, da Carta magma, igualando homens e mulheres em termos de direitos e deveres (BRASIL, 1988).

Observa-se com isso, uma grande "conquista para a mulher", da qual pode usufruir os mesmos direitos que o homem. Entretanto, o que se percebe é que a mulher mesmo dando este grande salto, de sair da prisão do lar e adentrar no mercado de trabalho, ela, ainda, mantém uma jornada dupla e até tripla de trabalho enquanto o homem continua com os mesmos deveres dantes e sendo ainda mais valorizado em termos financeiros.

Mas a história mostra que essa conquista decorre de grandes lutas e um tempo considerável. Dessa forma, Barros (2010) diz que o direito do trabalho surge na Europa onde o mundo era marcado pela desigualdade econômica e social e que tal fenômeno tornou-se essencial para intervenção do Estado por meio de uma legislação, predominantemente, imperativa de força.

Seguindo esse pensamento, a referida autora ressalta a importância do Tratado de Versailles, em 1919, trazendo em seu bojo o artigo 427, que por sua vez não admitia que $o$ trabalho fosse tratado como mercadoria, assegurando aos empregados jornada de trabalho de oito horas diárias, igualdade de salário, descanso semanal 
remunerado, inspeção do trabalho, salário-mínimo e, ainda, garantia de tratamento especial à mulher e ao menor além de dispor sobre direito sindical.

Nessa linha, o Art. 226 da Constituição Federal de 1988 em seus parágrafos $5^{\circ}$ e $7^{\circ}$, respectivamente, iguala direitos e deveres de homens e mulheres em relação à sociedade conjugal e coloca o planejamento familiar como direito a ser exercido pelo casal (THURLER e BANDEIRA, 2010).

Mediante tais direitos adquiridos, a taxa de participação feminina no mercado de trabalho saltou de 32,9\% para 52,7\% em quase três décadas (de 1981 a 2009), segundo dados da Pesquisa Nacional por Amostra de Domicílios - PNAD (IBGE, 2019).

Ainda, segundo dados da PNAD (2009) enquanto as mulheres casadas ou vivendo em união consensual, provedoras de domicílio ou não, gastavam em média 30 horas semanais nos afazeres domésticos, esse número caía para perto de 12 horas, no caso dos homens.

Ainda em consonância com dados do Instituto Brasileiro de Geografia e Estatística IBGE (2015), o crescimento da inserção feminina no mercado de trabalho também é evidenciado pela variação da população ocupada que avançou $21,9 \%$, enquanto o aumento da população masculina efetivamente no mercado de trabalho foi de $16,3 \%$.

A mensuração do trabalho na sociedade numa perspectiva mais ampla não consiste apenas naquele realizado em troca de uma remuneração. Neste sentido, considerase ainda aquele realizado no âmbito dos domicílios voltado para as atividades domésticas e de cuidado, que consome também uma parcela significativa do tempo das pessoas.

De acordo com uma análise das condições e vida da população brasileira apresentada pela Síntese de Indicadores Sociais - SIS (2015), em 2014, 90,7\% das mulheres ocupadas realizavam afazeres domésticos e de cuidados. Um quadro que pouco se alterou nos últimos anos considerando que, em 2004, este percentual era $91,3 \%$, o 
que mostra que a maior participação das mulheres no mercado de trabalho não implica numa substituição de trabalho e sim, no acúmulo.

Entretanto, apesar da maior dinâmica populacional feminina, o número de homens ocupados que realizam afazeres domésticos e cuidados na última década teve um aumento de $29,3 \%$, enquanto na população feminina essa variação foi de $21,0 \%$ (SIS, 2015).

Esses dados evidenciam que na atualidade, alguns homens já conseguem partilhar com as mulheres os afazeres domésticos em decorrência da nova geração feminina não se apegar tanto ao modelo patriarcal. Nesse sentido, Bourdieu (1999, p. 108), vem acrescentar que:

[...] o aumento do número de mulheres que trabalham não pode deixar de afetar a divisão de tarefas domésticas e, ao mesmo tempo, os modelos tradicionais masculinos e femininos, acarretando, sem dúvida, consequências na aquisição de posições sexualmente diferenciadas no seio da família: pode-se, assim, observar que as filhas de mães que trabalham têm aspirações de carreira mais elevadas e são menos apegadas ao modelo tradicional da condição feminina.

Esses dados vislumbram que ainda há muito que se fazer para que a diferença entre homens e mulheres diminua. Para tanto, vale explicitar que mesmo com essa dupla jornada, a mulher continua perdendo em termos de direitos previdenciários, visto que a diferença na idade mínima entre homens e mulheres proposta por Jair Bolsonaro em sua Reforma da Previdência (2019) não é suficiente para compensar a dupla jornada de trabalho à qual boa parte das mulheres está submetida.

Em virtude de acumularem sua ocupação com os afazeres domésticos, a mulher, como já foi dito anteriormente, trabalha mais horas por semana do que os homens sem serem remuneradas e sem contar esse tempo para previdência.

Trabalhadores urbanos podem pleitear a aposentadoria por idade aos 65 anos e trabalhadoras, aos 60 . Em atividades rurais, as idades são de 60 e 55, respectivamente. A proposta de Reforma da Previdência apresentada por Jair Bolsonaro quer implementar uma idade mínima para todo mundo, inclusive os que hoje se aposentam por tempo de contribuição, estabelecendo 65 anos, para homens, e 62, para 
mulheres, na cidade, e 60 para ambos no campo. O tempo mínimo de contribuição passaria de 180 meses (15 anos) para 240 (20 anos) (REFORMA DA PREVIDÊNCIA, 2019).

Esta proposta apresentada vem ignorar a jornada dupla reconhecida pela Assembleia Constituinte, em 1988, após a mobilização da sociedade civil, para fins de aposentadoria por idade, para tentar compensar parte de um sistema social e economicamente injusto (BRASIL, 1988).

Mediante tal exposição, questiona-se: será que esses três anos são suficientes para equilibrar essa discrepância entre homens e mulheres? Já se discute várias propostas no Congresso a fim de diminuir a carência mínima para todas as mulheres, no entanto vale ressaltar que não se trata de lacunas por falta de formação, de competência ou falta de dedicação, mas sim pelo machismo que impera até hoje em todos os campos da sociedade e, sobretudo na política.

\section{RESULTADOS E DISCUSSÃO}

A idade das entrevistadas variou de 19 a 66 anos com uma idade média entre elas de 36 anos. Em relação a escolaridade das entrevistadas, esta variou de fundamental incompleto até pós-graduação, segundo o gráfico 01 . Já em relação ao estado civil, a maioria das entrevistadas era casada, totalizando $46 \%$, seguido de $24 \%$ de entrevistadas solteiras, $18 \%$ de divorciadas e, por fim, $12 \%$ de viúvas, de acordo com gráfico 02. 
Gráfico 01: escolaridade

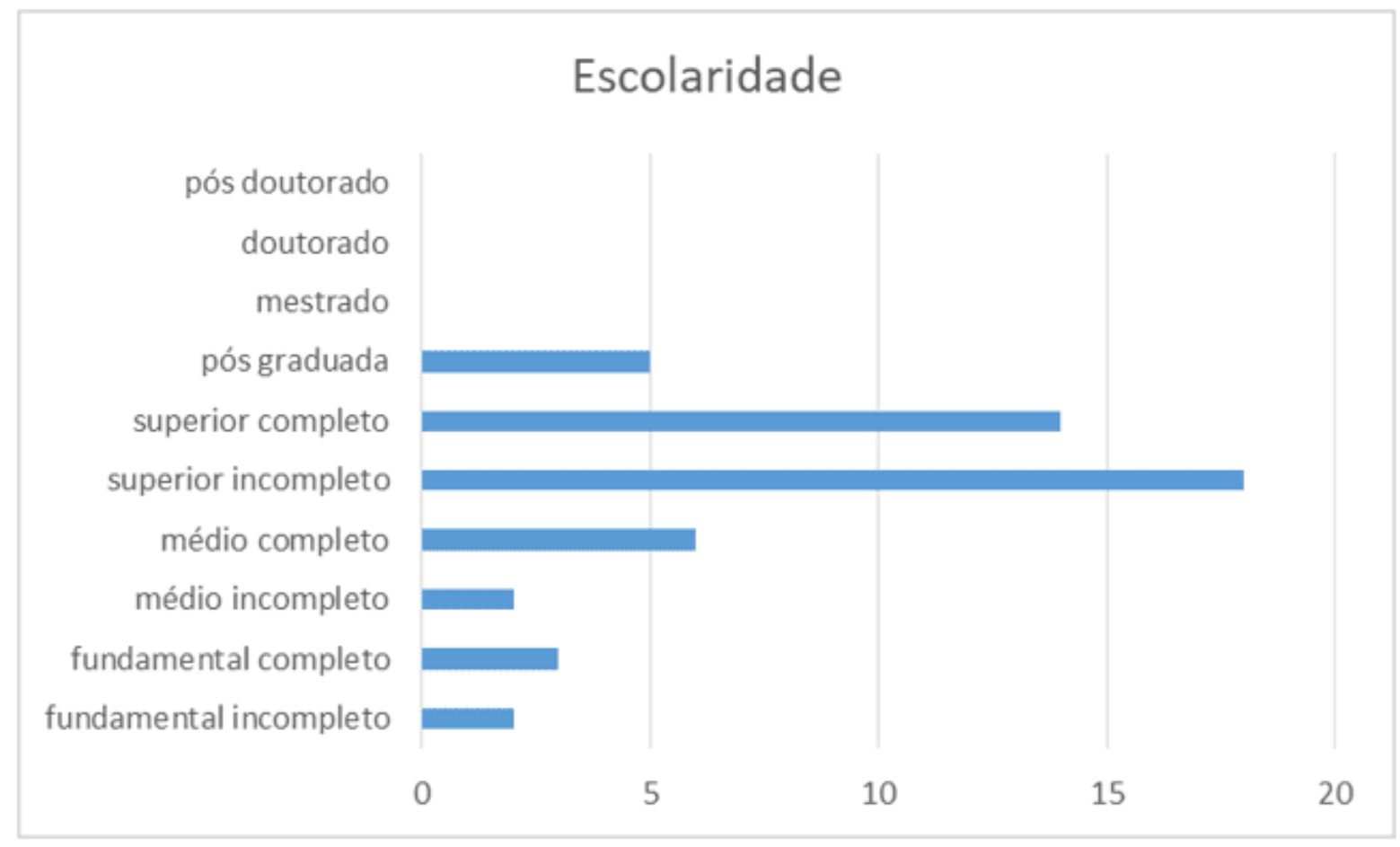

Fonte: Araújo; Fagundes; Souza (2019)

De acordo com o gráfico 01, conclui-se, que apesar da ocupação, ainda assim, as mulheres uruaçuenses conseguem dedicar-se aos estudos, uma vez que, $26 \%$ das entrevistadas já concluíram o ensino superior e $36 \%$ possuem o superior incompleto o que demonstra a vontade da mulher em se capacitar para o mercado de trabalho.

Além disso, os indicadores sociais do IBGE, publicados em 2016, evidenciaram uma tendência geral de aumento de escolaridade das mulheres em relação aos homens, o qual se quantifica que as mulheres atingem um nível de instrução superior quanto em comparação aos homens. Ainda segundo a publicação, 13,5\% dos homens com 25 anos de idade ou mais têm ensino superior, ao passo que esse quantitativo é maior para as mulheres com 16,9\% (IBGE, 2016). 
Gráfico 02: Estado civil

\section{ESTADO CIVIL}

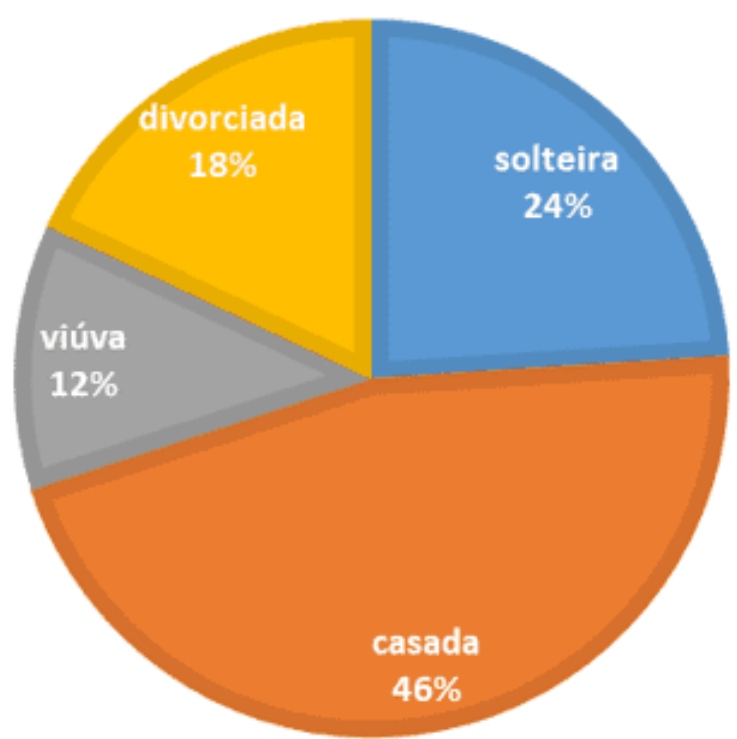

Fonte: Araújo; Fagundes; Souza (2019)

Observando o gráfico 02 , evidencia-se o caráter heterogêneo da pesquisa, pois foi entrevistado mulheres de diferentes estados civis, desde a solteira até a viúva. Sendo assim, de acordo com os dados coletados, notou-se que independentemente do estado civil, com raras exceções, a dupla jornada de trabalho está presente.

Já em relação à raça/cor foi constatado que $44 \%$ das entrevistadas se autodeclararam pardas, em seguida de brancas, somando $26 \%$ e $18 \%$ de se autodeclararam pretas. Além de 10\% se declararem amarelas e apenas 2\% indígenas, segundo gráfico 03.

Os dados encontrados na pesquisa, conforme demonstra gráfico 03, não corroboram com os dados publicados pelo último censo realizado pelo IBGE (2019), o qual constatou que $49 \%$ da população brasileira se autodeclara branca e apenas $13,6 \%$ se autodeclaram pardas. 
Gráfico 03: Raça/Cor

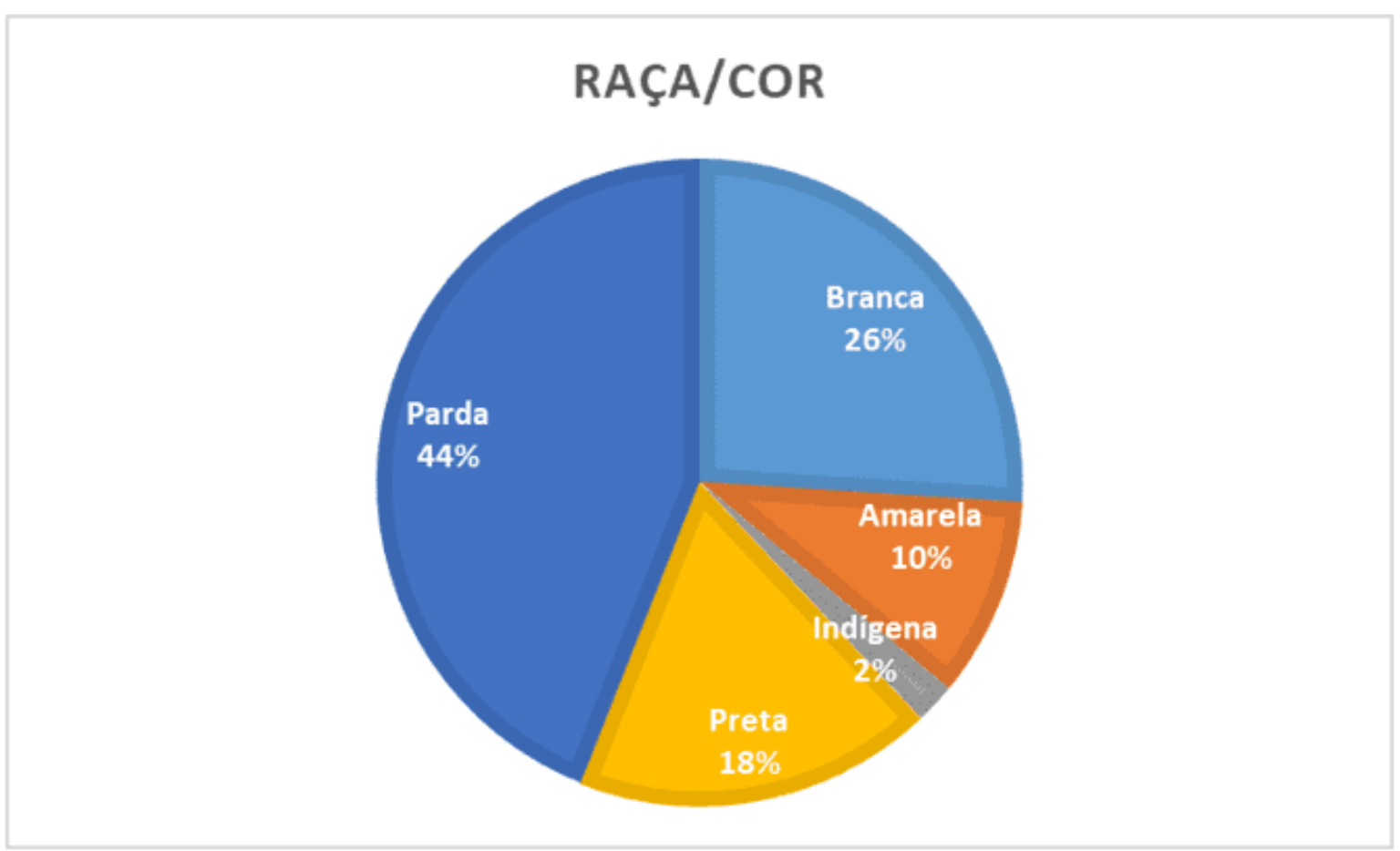

Fonte: Araújo; Fagundes; Souza (2019)

Já em relação ao questionamento principal do estudo sobre a temática da dupla jornada da mulher, ou seja, o revezamento da mulher entre as atividades domésticas em casa e o trabalho remunerado fora de casa, foi questionado, inicialmente, se as entrevistadas possuíam emprego fora de casa, o qual se obteve a resposta de que $96 \%$ das entrevistadas possuíam emprego. 
Gráfico 04: Trabalho fora do ambiente doméstico

\section{VOCÊ TRABALHA FORA?}

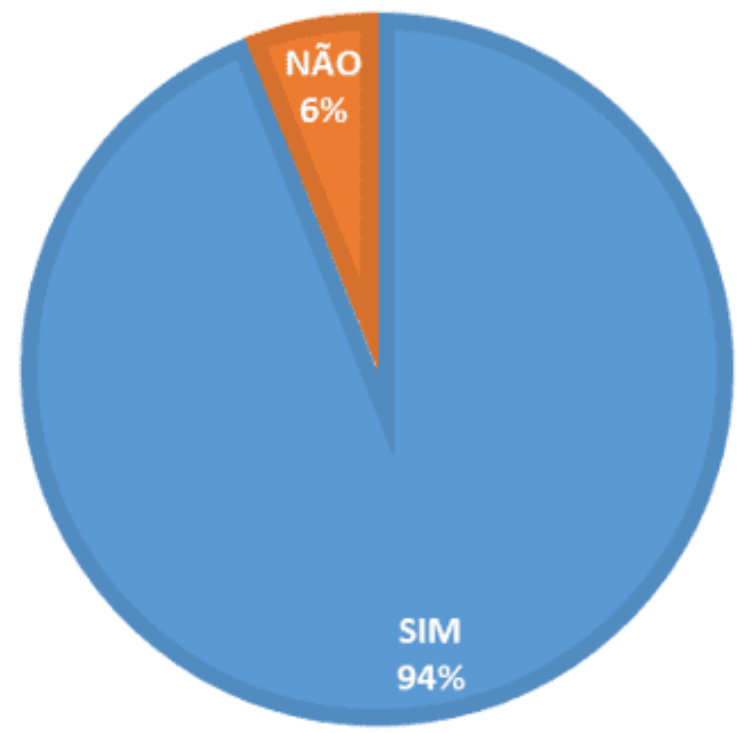

Fonte: Araújo; Fagundes; Souza (2019)

Os dados obtidos foram diferentes dos publicados por uma pesquisa realizada pelo IBGE (2008) nas principais capitais do país: Recife, Salvador, Belo Horizonte, Rio de Janeiro e São Paulo, feita em 2008, que resultou na porcentagem de $43,1 \%$ das mulheres entrevistadas possuírem emprego fora de casa, o que demonstra, que apesar da diferença amostral, as mulheres uruaçuenses estão mais inseridas no mercado.

Diante dos dados apresentados, não se sabe precisar quais os fatores levam a mulher uruaçuense ao mercado de trabalho, uma vez que a psicóloga Zimeo (2012) elencou os três fatores que motivam a mulher a trabalhar: realização pessoal, profissional ou necessidade financeira.

Quando questionado sobre os afazeres domésticos e se a responsabilidade por eles era apenas da mulher ou compartilhada por mais alguém, $73 \%$ das entrevistadas responderam ser apenas responsabilidade delas os afazeres domésticos, segundo o gráfico 5. Ou seja, não tem a ajuda de ninguém em casa. Já as poucas que 
responderam contar com a ajuda de alguém, citaram o marido, filhos e diarista para compartilhar essa responsabilidade.

Percebe-se com isso, que elas não conseguiram se desligar das funções e tarefas do lar, mesmo trabalhando fora, o que Ihes ocasionou uma sobrecarga e mais responsabilidades.

Com isso pode se deduzir que segundo Detoni; Lages e Sarmento (2015), "trabalhar fora de casa" foi um dos caminhos encontrados para garantir novos espaços de atuação, não conseguindo, no entanto, descartar o "trabalho dentro de casa", o preço por tanta motivação para a emancipação tem sido alto. (DETONI; LAGES e SARMENTO, 2015, p. 3).

Gráfico 05: Responsabilidade pelos afazeres domésticos.

\section{TEM ALGUÉM QUE AJUDA EM CASA?}

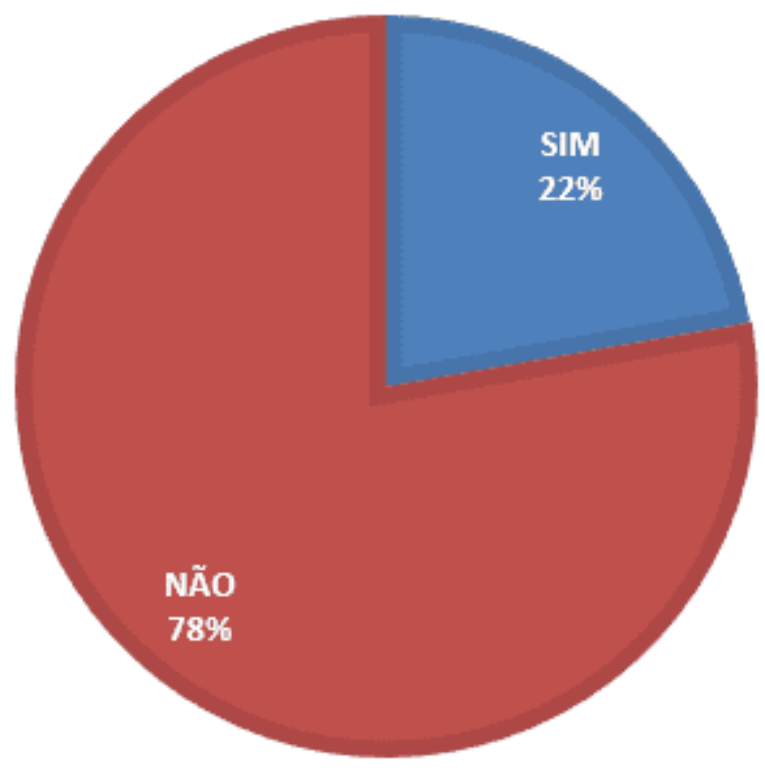

Fonte: Araújo; Fagundes; Souza (2019)

Sobre essa divisão da responsabilidade pelos afazeres domésticos, o IPEA (2008), mostra que é uma questão cultural a atribuição da mulher em ser responsável pela 
casa. Além disso, afirma que quando os homens as auxiliam nesta tarefa, eles são responsáveis apenas por tarefas de menor complexidade, a exemplo: compras no supermercado ou levar crianças na escola. O que resulta em uma jornada de trabalho de 7,5 horas semanais a mais para as mulheres.

Como é de notório conhecimento, as mulheres são menos valorizadas financeiramente no mercado de trabalho, por isso, foi questionado se as entrevistadas ganhavam mais ou menos que os seus companheiros. Como resposta, obteve-se que $86 \%$ das entrevistadas afirmaram receber menos que o seu companheiro.

Gráfico 06: Discrepância salarial entre homens e mulheres.

\section{VOCÊ GANHA MAIS QUE SEU COMPANHEIRO?}

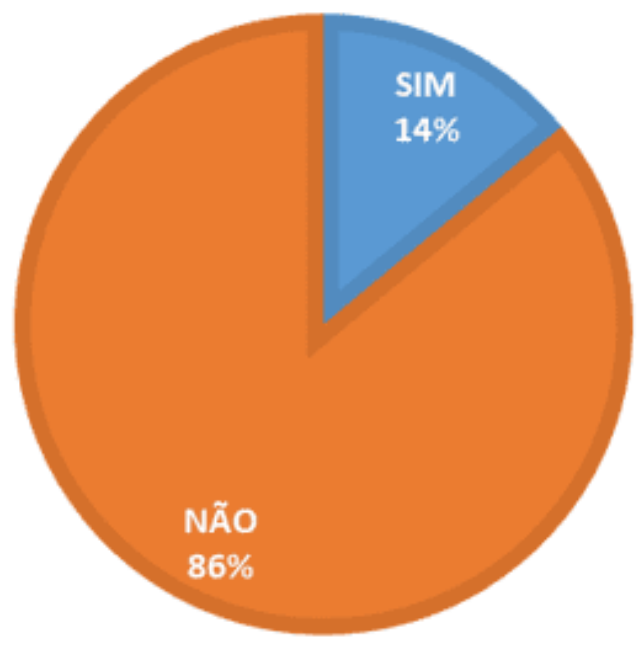

Fonte: Araújo; Fagundes; Souza (2019)

Apesar dessa realidade de discrepância entre os salários masculinos e femininos, desde 2016, essa diferença tem diminuído, uma vez que o salário da mulher subiu $2,6 \%$, enquanto no mesmo ano, o do homem subiu apenas 1,8\%. Mas ainda não é o ideal, visto que as mulheres ganham $85,1 \%$ dos salários dos homens. O que traduz numa média salarial nacional de $R \$ 2.708,71$ para as mulheres e $R \$ 3.181,87$ para os homens, segundo dados da Agência Brasil (2018). 
Mesmo em meio a esta dualidade de maior jornada de trabalho e menor remuneração salarial ainda sim, as mulheres se consideram independentes. Esses dados foram vislumbrados tanto na atual pesquisa, a qual constatou que $80 \%$ das entrevistadas se consideram independente, segundo gráfico 07 .

Gráfico 07: Independência das mulheres

\section{VOCÊ SE CONSIDERA INDEPENDENTE?}

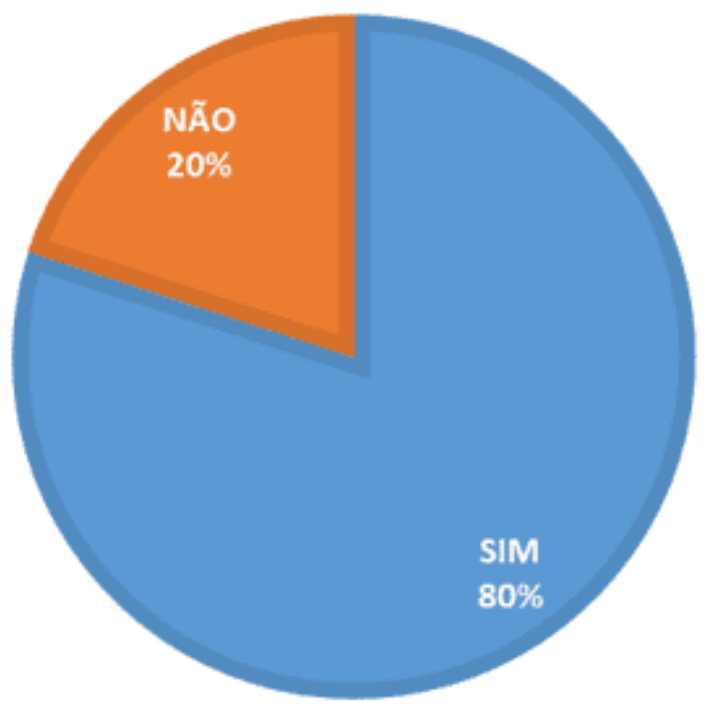

Fonte: Araújo; Fagundes; Souza (2019)

Por fim, foi indagado às entrevistadas se as mesmas se sentiam felizes pelo fato de serem mulheres. Obteve-se um resultado de $78 \%$ das entrevistadas se considerarem felizes. Foi perguntado ainda, de maneira subjetiva, o motivo pelo qual as entrevistadas se sentiam felizes ou não pelo fato de serem mulheres.

A maioria das entrevistadas que responderam afirmativamente, relacionaram essa felicidade ao fato de poderem constituir família, por meio da maternidade. Já as que responderam negativamente, relacionaram ao motivo da desvalorização da mulher, que em muitas vezes não é reconhecida diante de todas as atribuições exercidas. 


\section{CONSIDERAÇÕES FINAIS}

Pode concluir-se, então, que culturalmente, sempre foi atribuída às mulheres a responsabilidade das inúmeras tarefas conhecidas coletivamente como "tarefas domésticas", por esse motivo, atribui-se o termo dupla jornada, uma vez que a mulher precisa conciliar essas tarefas com o trabalho remunerado.

De maneira geral, o pensamento social brasileiro, no que diz respeito a posição da mulher, ainda está enraizado na casa grande e senzala. E é neste contexto que os conflitos surgem numa tentativa de articulação entre o trabalho não remunerado e o trabalho remunerado, pois as mulheres avançaram no mercado de trabalho e, em contrapartida, os homens ainda estão muito aquém na esfera doméstica.

Mediante os dados coletados, percebeu-se que essa realidade também está inserida no município de Uruaçu, uma vez que, as mulheres uruaçuenses trabalham fora, são responsáveis pelos afazeres domésticos, possuem um nível considerado de escolaridade e, ainda sim, ganham menos que os homens.

Mesmo com todo o contexto histórico de evolução, advindos das várias lutas das mulheres, que culminou na inserção de igualdade, prevista na Constituição Brasileira de 1988, em seu Art. 226, o qual reza pela igualdade de direitos e deveres de homens e mulheres em relação à sociedade conjugal e coloca o planejamento familiar como direito a ser exercido pelo casal (BRASIL, 1988).

Todavia, é mister destacar que esta prerrogativa legal ainda não garante a real igualdade entre homens e mulheres, principalmente no que tange a dupla jornada de trabalho atribuída apenas às mulheres.

Diante do exposto, nota-se que "trabalhar fora de casa" foi um dos caminhos encontrados para garantir novos espaços de atuação, não conseguindo, no entanto, descartar o "trabalho dentro de casa", o preço por tanta motivação para a emancipação tem sido alto. 
No entanto, fazem-se necessários maiores investimentos em políticas públicas no sentido de garantir uma valorização trabalhista, até mesmo em termos de direitos previdenciários, uma vez que esse quantitativo de horas trabalhadas não é contabilizado para efeitos de aposentadoria.

Salienta-se que essa pesquisa não tem o propósito de esgotar o assunto, mas sim, para que haja maior interesse em se pesquisar e aprofundar no tema em questão, servindo de incentivo para o surgimento de novas pesquisas inerentes à esta temática.

\section{REFERÊNCIAS}

BANDEIRA, Lourdes; Thurler, Ana Liési. A vulnerabilidade da mulher à violência doméstica: aspectos históricos e sociológicos. 2010.

BARBOSA, Esdras da Silva. Ensino de História e RAP: classe, raça e gênero como possibilidades de diálogo nas aulas de História. 2017. Monografia - Universidade de Brasília.

Brasília, 2017.

Disponível

em: https://bdm.unb.br/bitstream/10483/18889/1/2017_EsdrasdaSilvaBarbosa.pdf Acesso em: $18 / 05 / 2019$

BARROCAL, André. Mulheres Trabalham 7,5 horas a mais que os homens. Carta Capital. São Paulo, 6 de maio de 2019. Disponível em: http://www.cartaeducacao.com.br/aulas/medio/a-dupla-jornada-dasmulheres/ Acesso em: 13/03/2019.

BARROS, Alice Monteiro de. Curso de Direito do Trabalho. São Paulo. 2010, 67.

BEAUVOIR, Simone. O segundo sexo. São Paulo: Difel-Difusão Europeia Do Livro, 1960.

BOURDIEU, Pierre. A dominação masculina. Trad. Maria Helena Kühner. Rio de Janeiro: Bertrand Brasil, 1999.

BRASIL. Constituição (1988). Constituição da República Federal do Brasil. Brasília, DF: Senado Federal, 1988 
IBGE. Síntese de Indicadores Sociais (SIS) - Uma análise das condições de vida da população brasileira 2015. Disponível em: Disponível em: https://agenciadenoticias.ibge.gov.br/agencia-sala-de-imprensa/2013-agencia-denoticias/releases/24266-mulheres-dedicam-mais-horas-aos-afazeres-domesticos-ecuidado-de-pessoas-mesmo-em-situacoes-ocupacionais-iguais-a-dos-homens Acesso em 25 maio de 2019

IBGE. Pesquisa Nacional por Amostra de Domicílio. 2011

IBGE. Pesquisa Nacional por Amostra de Domicílio. 2019.

IPEA. Instituto de Pesquisa Econômica Aplicada. 2015. Disponível em: www.ipea.gov.br-;

IBGE. Diretoria de Pesquisas Coordenação de Trabalho e Rendimento Pesquisa de Orçamentos Familiares 2007-2008. Disponível em: https://biblioteca.ibge.gov.br/visualizacao/livros/liv101670.pdf

IBGE. Diretoria de Pesquisas Coordenação de Trabalho e Rendimento Pesquisa de Orçamentos Familiares 2007-2008

DETONI, Carolina; LAGES, Sônia Regina Corrêa; SARMENTO, Sandra Carrato. OPreço da Emancipação Feminina - Uma reflexão sobre o estresse gerado pela dupla jornada de trabalho. Disponível em:<http://portal.estacio.br/media/3345423/8-oprecoemancipacao-feminina-reflexao-sobre-estresse-gerado-dupla-jornadatrabalho.pdf $>$. Acesso em: 09 mar. 2019.

DICIONÁRIO PRIBERAM DA LÍNGUA PORTUGUESA [em linha], 20082013. Disponível em:< https://dicionario.priberam.org/escrava> Acesso em 22-04-2019.

GIL, Antônio Carlos Métodos e técnicas de pesquisa social. 6. ed. - São Paulo: Atlas, 2008.

LAKATOS, Eva Maria; MARCONI, Marina de Andrade. Fundamentos de metodologia científica. 5. ed. São Paulo: Atlas, 2003. 
LADEIRA, Kátia de Freitas. Dupla jornada da mulher e qualidade de vida: a influência do nível socioeconômico nas estratégias de conciliação entre o tempo laboral e o tempo familiar. Dissertação (Mestrado em Economia Doméstica) - Universidade Federal de Viçosa, Viçosa, 2000.

MARTINS, Clitia Helena Backx. Dupla jornada de trabalho: desigualdade entre homens e mulheres. Carta de Conjuntura FEE. Porto alegre, ano 22, n0ㄴ, 2013. Disponível em: <http://carta.fee.tche.br/article/dupla-jornada-de-trabalhodesigualdade-entre-homens-e-mulheres/acessado> Acesso em: 04/04/2019.

MATOS, Maria Izilda; BORELLI, Andrea. Espaço feminino no mercado produtivo. In: PINSKY, Carla Bassanezi; PEDRO, Joana Maria (orgs.). Nova História das Mulheres no Brasil. São Paulo: Editora Contexto, 2012, p. 126-14

PINHEIRO, Luana Simões. O trabalho nosso de cada dia: determinantes do trabalho doméstico de homens e mulheres no Brasil. 2018. 329f. Tese - (Doutorado em Psicologia) Universidade de Brasília. Brasília, 2018.

PRIORI, Mary Del (ORG). História das mulheres no Brasil. São Paulo, SP. Editora Pinsky, 2004.

SAKAMOTO, Leonardo. Reforma seria diferente se mulheres fossem $50 \%$ e não $15 \%$ da Câmara? Blog do Sakamoto. São Paulo, 20 de fev. de 2019. Disponível em: $<$ https://blogdosakamoto.blogosfera.uol.com.br/2019/02/28/reforma-da-previdenciaconsidera-a-dupla-jornada-de-trabalho-das-mulheres/?> Acesso em: 12/05/2019

SCOTT, Ana Silvia. O caleidoscópio dos arranjos familiares. In: PINSKY, Carla Bassanezi; PEDRO, Joana Maria (Orgs.). Nova História das Mulheres no Brasil. São Paulo: Contexto, 2012. p. 15-42. SCOTT, Joan W. A mulher trabalhadora. In: DUBY, Georges; PERROT, Michelle (Orgs.). História das mulheres no Ocidente. Porto: Edições Afrontamento, vol. IV, 1991. p. 443-475.

SILVA, Christiane Leolina Lara; ARAÚJO, José Newton Garcia de; MOREIRA, Maria Ignez Costa; BARROS, Vanessa Andrad. O trabalho de empregada doméstica e seus 
impactos na subjetividade. Psicologia em Revista. Belo Horizonte, v. 23, n. 1, 2017. Disponível em: < http://pepsic.bvsalud.org/scielo.php?script=sci_arttext\&pid=S167711682017000100028 > Acesso em: 21/05/2019

SÍNTESE DE INDICADORES SOCIAIS. Uma análise das condições de vida da população brasileira: 2020. IBGE, Coordenação de População e Indicadores Sociais. - Rio de Janeiro: IBGE, 2020. 148 (Estudos e Pesquisas. Informação Demográfica e Socioeconômica, ISSN 1516-3296; n. 43)

ZIMEO, Adélia Ester Maame. Anseios da Vida. 2012. São Paulo. Disponível em: https://www.blogger.com/profile/00388036168290317588

\section{APÊNDICE - REFERÊNCIA DE NOTA DE RODAPÉ}

4. Escrava: Mulher cativa. Que está dominada por uma ideia ou sentimento = dependente; Indivíduo que foi destituído de sua liberdade e que vive em absoluta sujeição a alguém que a trata como um bem explorável e negociável. Mulher que está sujeita à submissão radical diante de qualquer homem; trabalha em demasia sem remuneração.

Enviado: Junho, 2021.

Aprovado: Novembro, 2021. 